\title{
Cryopreservation of Winter-dormant Apple Buds Using Two-step Freezing
}

\author{
Jung Yoon $\mathrm{Yi}^{1}{ }^{*}$, Gi An Lee ${ }^{1}$, Sok Young Lee ${ }^{1}$, Jong Wook Chung ${ }^{1}$, Il Sup Shin ${ }^{2}$ \\ ${ }^{1}$ National Academy of Agricultural Sciences, RDA, Suwon, 441-853, Korea \\ ${ }^{2}$ National Institute of Horticultural and Herbal Sciences, RDA, Suwon, 440-706, Korea
}

\begin{abstract}
Winter apple buds germplasm was cryopreserved in the Korean Genebank to back up the genetic resources maintained by field collections. We examined the standard two-step freezing protocol for the cryopreservation of winter buds of apple germplasm developed by National Center for Genetic Resources Preservation (NCGRP) in the USA. This protocol requires desiccation of the stem explants containing a single dormant bud to $30 \%$ moisture content, cooling at a rate of $1{ }^{\circ} \mathrm{C} / \mathrm{h}$ to $-30^{\circ} \mathrm{C}$ for 24 hours, followed by rapid immersion in liquid nitrogen. To evaluate the viability of cryopreserved buds after at least 24 hours, the thawed and rehydrated segments are transferred to a greenhouse and used for vegetative propagation by chip budding onto rootstock or by in vitro sprouting. To optimize the protocol for the cryopreservation of winter-dormant apple buds suitable for Korean climate, we tested several treatments, including different degrees of desiccation, pre-freezing temperatures, and pre-freezing rates. The highest regeneration rates were obtained from cryopreserved samples with $35 \%$ moisture content, $-35^{\circ} \mathrm{C}$ pre-freezing temperature, and $1{ }^{\circ} \mathrm{C} / \mathrm{h}$ pre-freezing rate. Finally, using our two-step freezing method, 14 accessions of apple germplasm were cryopreserved successfully, with an average regeneration rate of $55.0 \%$.
\end{abstract}

Keywords Apple, Cryopreservation, Dormant bud, Two-step freezing

\section{INTRODUCTION}

To improve breeding efforts, it is necessary to conserve valuable germplasm. Traditionally, the germplasm of woody fruit crops such as Malus sp. is preserved through field establishment. However, the maintenance of woody perennials in the field is very expensive. Sometimes, only two replicates are kept for any given clone, which can be lost through disease or adverse environmental conditions. Cryopreservation is an alternative for the long-term storage of plant germplasm and is preferred especially for clonally propagated germplasm.

Malus germplasm can be cryopreserved using buds from either in vitro or ex vitro plants (Tyler and Stushnoff 1988a; Wu et al. 2001). Sakai (1960) first described the cryopreservation of dormant vegetative buds from woody, cold-hardy plants, and Sakai and Nishiyama (1978) first demonstrated it for apple. Protocols based on the endogenous production of cryoprotectants in dormant apple buds were refined by Stushnoff (1987), Tyler and Stushnoff (1988a, 1988b), and Tyler et al. (1988) with recovery using grafting. Subsequently, two-step freezing protocol for the cryopreservation of dormant winter buds of apple plants was developed at the National Center for Genetic Resources Preservation (NCGRP) in Fort Collins, Colorado using material grown under a continental climate (Forsline $e t$ al. 1998, 1999; Towill and Ellis 2008; Towill et al. 2004). This protocol involves excision of naturally- hardened explants comprising a single, dormant bud on a $35 \mathrm{~mm}$ stem segment, followed by desiccation at $-5^{\circ} \mathrm{C}$ and cooling to $-30^{\circ} \mathrm{C}$ before transfer to liquid nitrogen. Thawed material is recovered by grafting the bud together with a small piece of cortical tissue onto a young, recipient apple trees. Recently, the technique has been used in many other countries,

Received September 4, 2013; Revised September 24, 2013; Accepted September 24, 2013; Published September 30, 2013

*Corresponding author JungYoon Yi, naaeskr@korea.kr, Tel: +82-31-299-1886, Fax: +82-31-299-1839 
especially in Europe, such as Denmark, Germany, Switzerland, and Italy, to adapt the protocol to different winter climates (Lambardi 2012). In Korea, approximately 31,167 ha of apples were cultivated in 2011 (http:// www.karin.re.kr). Apple is one of the most important deciduous fruit crops that can be improved through breeding. Therefore, preserving valuable germplasm is crucial for successful apple breeding program.

Cryopreservation using the dormant-bud technique has the advantage of allowing the direct transfer of accessions from the field to the tank and vice versa with no tissue culture process, which is necessary with the PVS2-based vitrification technique before and after storage in liquid nitrogen (Lambardi 2012). Therefore, the cryopreservation of apple dormant buds requires only about $40 \%$ of the time and $50 \%$ of the labor necessary for the shoot-tip vitrification approach (Lambardi 2012).

Here, we report the optimized standard two-step freezing method to induce a higher rate of shoot formation from cryopreserved vegetative apple buds and to implement long-term conservation of apple germplasm in the Korean Genebank.

\section{MATERIALS AND METHODS}

\section{Sample collection}

Scion samples containing quiescent buds were collected in early January 2013, in a field at the National Institute of Horticultural and Herbal Science (NIHH), Suwon. The stems were collected when the temperature was about or below $0^{\circ} \mathrm{C}$ for at least $72 \mathrm{~h}$. Collected scions were wrapped and stored at $-5^{\circ} \mathrm{C}$ for cold acclimation for two weeks.

\section{Sample processing}

The scions were cut into $35 \mathrm{~mm}$-long, single-node sections with the bud in the central position. They were categorized into three groups according to section diameter: thin $(5.5 \mathrm{~mm})$, intermediate $(8.2 \mathrm{~mm})$, and thick $(10.2 \mathrm{~mm})$. The bud sections were spread on trays and held unsealed in a freezer at $-5^{\circ} \mathrm{C}$ to dehydrate. Desiccation occurs more quickly for smaller scion diameters. For each accession or treatment, five twig samples were prepared from each of the three size groups to monitor the level of desiccation. Each twig in two bundles of samples was weighed immediately after cutting, and the individual twig in one group was oven-dried at $85^{\circ} \mathrm{C}$ to determine their moisture content on a fresh-weight basis. The individual twig in the other group were weighed daily. When the twigs reached the target moisture content, they were double wrapped in moisture-proof plastic to eliminate further desiccation and held at $-5^{\circ} \mathrm{C}$ until the liquid nitrogen treatment.

\section{Cooling and warming}

The sections were packaged in polyolefin tubes and cooled to $-25^{\circ} \mathrm{C}$ to $-40^{\circ} \mathrm{C}$ at rates of $0.5 \sim 2^{\circ} \mathrm{C} / \mathrm{h}$ for 24 hours using a programmable refrigerator (Dasol Scientific, Hwaseong, South Korea). Then, the tubes were immersed quickly in liquid nitrogen vapor for at least 24 hours. Warming was accomplished by transferring the tubes to a $4^{\circ} \mathrm{C}$ room in containers with a moist peat where they were held for 14 days.

\section{Viability assessment}

Sprouting was accomplished by placing the basal ends of the sections in small plastic containers with commercial bleach. Grafting was performed using a chip budding technique with 1-year-old apple seedling rootstock. The budded rootstocks were held in a greenhouse and examined over a 2-month period for growth of the bud. Viability was assessed as the formation of a shoot from the grafted bud. The results were entered into the Germplasm Management System at the Rural Development Administration (RDA), South Korea.

\section{RESULTS AND DISCUSSION}

\section{Effect of dehydration}

Several levels of dehydration were tested to determine which water content is best for cryopreservation and whether a protocol without drying is applicable to two apple cultivars. Both cultivars had very high survival rates when the moisture content before sealing the sample tubes 
was $35 \%$ (Table 1). The survival of dormant vegetative buds that were dehydrated before cryopreservation was greater than that of non-dehydrated buds. Especially, the regeneration rate was significantly higher at $30 \sim 40 \%$ moisture contents compared with the non-dry freezing treatment (Table 1).

Some cold-hardy species can be cryopreserved without desiccation, including Malus baccata, Prunus virginiana, $P$. besseyi, and P. tenella. These should be harvested in midwinter, during the period of maximum cold hardiness, following a period of extreme cold exposure outdoors (Martha 2001). Other species must be desiccated to be able to survive in liquid nitrogen when they are harvested at any time, including Malus pumila, Prunus nigra, P. fruiticosa, and $P$. tomentosa. Yet other species require controlled acclimation and dehydration, e.g., Prunus armeniaca, $P$. avium, P. cerasus, and P. persica (Stushnoff 1987).

The cryopreservation method routinely applied at the NCGRP in the USA uses winter-harvested scions that are desiccated in the laboratory to $30 \%$ moisture before two-step cooling and storage in liquid nitrogen (Towill and Bonnart 2005). The method using desiccated winter buds has been effective for a range of species (Forsline et al. 1998; Towill et al. 2004), but drying and measuring water contents every day for $2 \sim 4$ weeks is time-consuming. Furthermore, the moisture content of the desiccated scions does not always conform to the value predicted by the testing procedure.

Therefore, we tested which water contents were effective for shoot regeneration and also to cooled nondesiccated sections to determine whether a drying step was necessary for successful cryopreservation. Lower survival rates were observed in non-desiccated compared with desiccated sections (Table 1) implying that desiccation before freezing is necessary for high survival rates after cryopreservation.

Grafting is labor-intensive, and the results cannot be determined for at least two months. For this study, we used sprouting as the main indicator of viability, but we also present results from some grafting tests. Grafting was done especially to demonstrate the recovery of samples that are cooled slowly.

\section{Effect of pre-freezing temperature and rate}

Scion sections of apple germplasm exposed to liquid nitrogen after cooling to $-25^{\circ} \mathrm{C} \sim-40^{\circ} \mathrm{C}$ showed significant levels of sprouting (Table 2). Most accessions cooled to $35^{\circ} \mathrm{C}$ and transferred to liquid nitrogen had significantly higher survival than those cooled to another temperature condition. Most buds on the scion grew, as illustrated for M. domestica cv. 'Hongro' (Fig. 1). In most treatments, cooling to $-35^{\circ} \mathrm{C}$ rather than to $-25,-30$, or $-40^{\circ} \mathrm{C}$ before transfer to liquid nitrogen significantly improved survival for most of the accessions tested. At $-40^{\circ} \mathrm{C}$, the survival rates decreased. Additionally, for the 'Hongro' and 'Chukwang' samples, the survival rate decreased when they were cooled to relatively higher temperatures $\left(-25^{\circ} \mathrm{C}\right.$, $-30^{\circ} \mathrm{C}$ ) before transfer to liquid nitrogen. Presumably, they

Table 1. Effect of desiccation on the regeneration rate of winter buds of 'Hongro' and 'Chukwang' cryopreserved in liquid nitrogen.

\begin{tabular}{ccccc}
\hline \hline \multirow{2}{*}{ Treatment } & \multicolumn{4}{c}{ Regeneration Rate (\%) } \\
\cline { 2 - 5 } & \multicolumn{3}{c}{ 'Hongro' } & 'Chukwang' \\
\cline { 2 - 5 } & -LN & + LN & 100.0 & + LN \\
\hline Non-Dry, Non-freezing & 100.0 & - & 97.8 & $47.3 \mathrm{~d}$ \\
Non-Dry, freezing & 97.7 & $44.6 \mathrm{~d}^{\mathrm{z}}$ & 98.2 & $67.3 \mathrm{~b}$ \\
$30 \%$, freezing & 95.9 & $70.3 \mathrm{~b}$ & 96.2 & $81.5 \mathrm{a}$ \\
$35 \%$, freezing & 98.3 & $85.4 \mathrm{a}$ & 99.9 & $60.3 \mathrm{c}$ \\
$40 \%$ freezing & 96.9 & $67.7 \mathrm{c}$ & 9
\end{tabular}

${ }^{\mathrm{z}}$ Mean separation within columns by Duncan's multiple range test at $5 \%$ level by $\mathrm{R}$ project ( $\mathrm{R}$ version 3.0.1) for statistical computing. 
were insufficiently freeze-desiccated and did not survive. Therefore, $-35^{\circ} \mathrm{C}$ is the optimum cooling temperature, in agreement with previous reports (Towill and Bonnart 2005), although other studies demonstrated different results (Tyler et al. 1988; Vogiatzi et al. 2012).

The cooling rate is also very crucial for successful cryopreservation. The sprouting assay at $1{ }^{\circ} \mathrm{C} / \mathrm{h}$ had a success rate of $85.4 \%$ in 'Hongro' and $81.5 \%$ in 'Chukwang', which were better than those for samples cooled at 0.5 or $2^{\circ} \mathrm{C} / \mathrm{h}$. Towill and Bonnart (2005) reported that the optimal cooling rate reflects the rate at which intracellular water migrates to the extracellular spaces and the time required to remove sufficient water to limit freezing injury. As shown in Table 3, it is thought that a cooling rate of $0.5^{\circ} \mathrm{C} / \mathrm{h}$ was longer than reported for most biological materials because of the size of the explants treated (Table 3). The optimal cooling rate was $1{ }^{\circ} \mathrm{C} / \mathrm{h}$, which is similar to most reports (Towill and Bonnart 2005; Tyler et al. 1988; Vogiatzi et al. 2012).

After warming, the samples were held overnight at $4^{\circ} \mathrm{C}$. This warming temperature was reasonable because the extent of freeze desiccation before transfer to liquid nitrogen would be increased. In both cases, sprouting and grafting were used to assess the viability after cryopreservation.

\section{Cryopreservation of apple germplasm}

We processed 14 accessions of apple germplasm. The accessions listed in Table 4 are arranged in descending
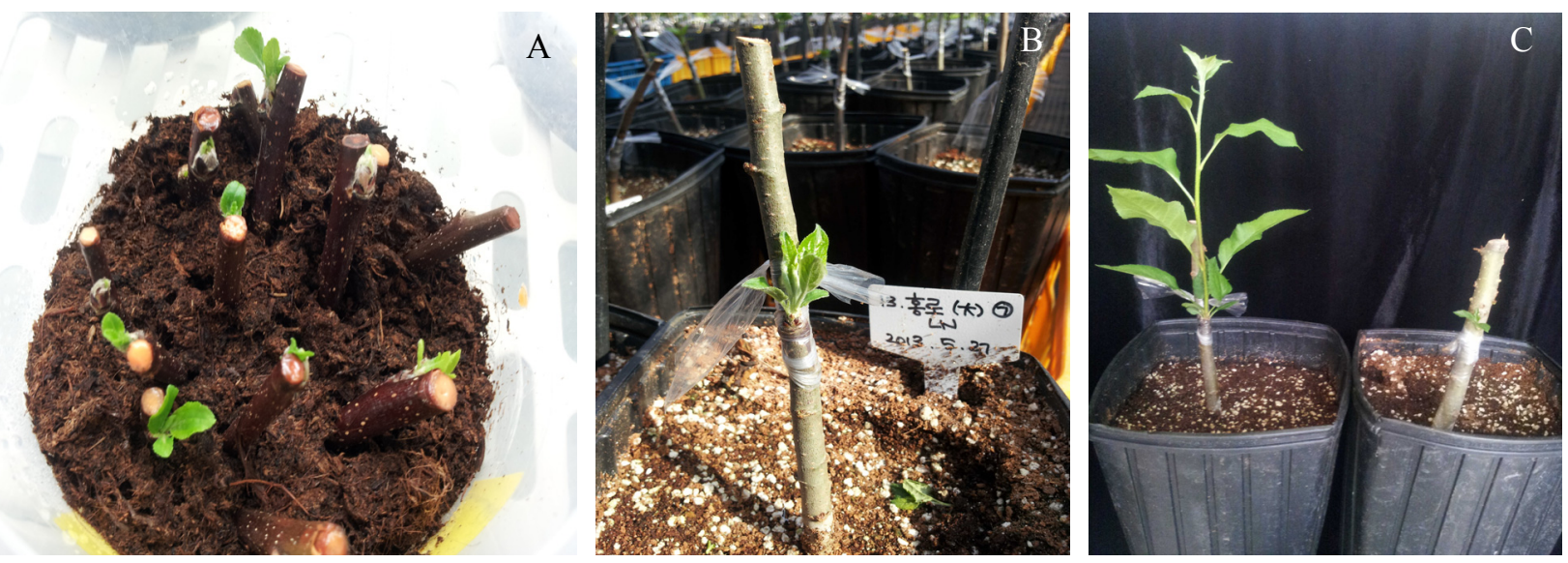

Fig. 1. Plant regenerated from cryopreserved winter bud of 'Hongro' apple stem segments: A) shoot formation from cryopreserved apple winter bud by in vitro cutting; B) budding of cryopreserved apple winter bud onto young seedling; C) comparison of the growth two months after budding of winter apple buds cryopreserved without LN (left) and with LN treatment (right).

Table 2. Effect of the pre-freezing temperature on the regeneration rate of winter buds of 'Hongro' and 'Chukwang' cryopreserved in liquid nitrogen.

\begin{tabular}{ccccc}
\hline \hline \multirow{2}{*}{ Pre-freezing Temperature } & \multicolumn{4}{c}{ Regeneration rates (\%) } \\
\cline { 2 - 5 } & \multicolumn{3}{c}{ 'Hongro' } & 'Chukwang' \\
\cline { 2 - 5 } & $-\mathrm{LN}$ & $+\mathrm{LN}$ & 98.3 & $+\mathrm{LN}$ \\
\hline$-25^{\circ} \mathrm{C}$ & 97.5 & $55.3 \mathrm{c}^{\mathrm{z}}$ & $98.3 \mathrm{c}$ \\
$-30^{\circ} \mathrm{C}$ & 100 & $73.3 \mathrm{~b}$ & 100 & $71.2 \mathrm{~b}$ \\
$-35^{\circ} \mathrm{C}$ & 97.7 & $85.4 \mathrm{a}$ & $81.5 \mathrm{a}$ \\
$-40^{\circ} \mathrm{C}$ & 96.5 & $58.3 \mathrm{c}$ & 97.2 & $44.3 \mathrm{~d}$ \\
\hline
\end{tabular}

${ }^{\mathrm{z}}$ Mean separation within columns by Duncan's multiple range test at $5 \%$ level by $\mathrm{R}$ project (R version 3.0 .1$)$ for statistical computing 
Table 3. Effect of the pre-freezing rate to $-35^{\circ} \mathrm{C}$ on the regeneration rate of winter buds of 'Hongro' and 'Chukwang' cryopreserved in liquid nitrogen.

\begin{tabular}{ccccc}
\hline \hline \multirow{3}{*}{ Pre-freezing Rates } & \multicolumn{4}{c}{ Recovery rates (\%) } \\
\cline { 2 - 5 } & \multicolumn{3}{c}{ 'Hongro' } & \multicolumn{3}{c}{ 'Chukwang' } \\
\cline { 2 - 5 } & $-\mathrm{LN}$ & $+\mathrm{LN}$ & 98.8 & $+\mathrm{LN}$ \\
\hline $0.5^{\circ} \mathrm{C} / \mathrm{h}$ & 95.9 & $61.2 \mathrm{~b}^{\mathrm{z}}$ & 100 & $58.3 \mathrm{~b}$ \\
$1^{\circ} \mathrm{C} / \mathrm{h}$ & 97.4 & $85.4 \mathrm{a}$ & $81.5 \mathrm{a}$ \\
$2^{\circ} \mathrm{C} / \mathrm{h}$ & 97.1 & $55.2 \mathrm{~b}$ & 98.2 & $59.3 \mathrm{~b}$ \\
\hline
\end{tabular}

${ }^{2}$ Mean separation within columns by Duncan's multiple range test at $5 \%$ level by $\mathrm{R}$ project ( $\mathrm{R}$ version 3.0.1) for statistical computing

order of survival rates following liquid nitrogen vapor exposure. The regeneration rates ranged from 41.1 to $85.4 \%$ with an average value of $55.0 \%$. According to RDA Genebank standards, an accession is successfully cryopreserved when $40 \%$ or more of liquid nitrogen-treated buds form a shoot. All accessions processed in this study met this standard (Table 4). Towill et al. (2004) reported the first cryopreservation of a large number of accessions of a clonally held Malus genus. Others have successfully applied the two-step cooling process to shoot tips from Pyrus species in vitro (Reed et al. 1998) and winter buds from field plants of mulberry, with plants that were recovered in tissue culture (Niino 1995). The two-step freezing method with dormant buds is very simple, allowing many Malus accessions to be processed, and it will improve germplasm conservation. We believe that this method can prevent the loss of apple germplasm from diseases such as fire blight (Erwinia amylovora) by preserving healthy cryopreserved dormant buds (Forsline and Aldwinckle 2002).

In many countries, it is essential to establish a system for the duplicate collection of clonally propagated fruit crops for long-term preservation (Martha 2001). Many reports have applied this system to various fruit species, including

Table 4. List of regenerated winter buds of 14 apple cultivars cryopreserved in liquid nitrogen vapor.

\begin{tabular}{ccccc}
\hline $\begin{array}{c}\text { Accession } \\
\text { number }\end{array}$ & Scientific name & Accession name & Recovery rates (\%) & No. of accessions conserved \\
\hline 249799 & Malus domestica & Hongso & $41.1 \pm 3.09$ & 150 \\
225513 & Malus domestica & Seohong & $43.3 \pm 5.77$ & 226 \\
249804 & Malus domestica & Picnic & $43.5 \pm 6.27$ & 90 \\
226029 & Malus domestica & Red Gold & $43.5 \pm 8.84$ & 65 \\
255854 & Malus domestica & Hwangok & $43.9 \pm 6.26$ & 250 \\
254759 & Malus domestica & Hwarang & $46.7 \pm 0.01$ & 320 \\
249800 & Malus domestica & Hongan & $48.6 \pm 9.90$ & 100 \\
249803 & Malus domestica & Greenball & $52.2 \pm 8.01$ & 30 \\
249255 & Malus domestica & Gamhong & $55.0 \pm 0.01$ & 400 \\
225511 & Malus domestica & Seokwang & $56.9 \pm 2.74$ & 560 \\
255536 & Malus domestica & Yeohong & $63.1 \pm 3.37$ & 280 \\
225602 & Malus domestica & Hwahong & $65.8 \pm 5.98$ & 100 \\
225578 & Malus domestica & Chukwang & $81.5 \pm 4.41$ & 100 \\
225596 & Malus domestica & Hongro & $85.4 \pm 6.01$ & 100 \\
Average & & 55.0 & \\
\hline
\end{tabular}


Malus, Amelanchier, Morus, and Prunus. Cryopreservation of dormant vegetative buds seems to be the best cryopreservation method because it is simple, inexpensive, and reliable. Additionally, this method is very practical because plants grafted using post-cryopreservation scions are induced to flower early hence period to harvesting is shortened.

In previous reports, the extent of cold hardiness in accessions was related to the success of cryopreservation (Forsline et al. 1998; Jenderek et al. 2011; Towill et al. 2004; Tyler and Stushnoff 1988). However, in this study we found no relationship between cold hardiness and the survival rates of cryopreserved germplasm, presumably because of incomplete knowledge of the extent of cold hardiness and the uneven health and nutrition conditions of the different accessions.

\section{CONCLUSION}

In this study, we designed several treatments to optimize two-step freezing method for the cryopreservation of winter-dormant apple buds under Korean climate. The highest regeneration rates were observed from cryopreserved samples with $35 \%$ moisture content, pre-freezed at $-35^{\circ} \mathrm{C}$, at a rate of $1{ }^{\circ} \mathrm{C} / \mathrm{h}$. Using our modified two-step freezing method, 14 apple accessions obtained from NIHH in Suwon were cryopreserved successfully, with an average regeneration rate of $55.0 \%$. This is the first trial of the preservation of fruit tree dormant buds in Korea, and findings of this study can be applied to preserve more apple collections in the Korean Genebank.

\section{ACKNOWLEDGMENT}

This study was supported by the Research Program for Agricultural Science \& Technology Development (Project No. PJ009369), National Academy of Agricultural Science, Rural Development Administration, Republic of Korea.

\section{REFERENCES}

Forsline PL, Aldwinckle HS. 2002. Natural occurrence of fire blight in USDA apple collection after 10 years of observation. The $9^{\text {th }}$ International Workshop on Fire Blight, New Zealand. Acta Horticulturae 590: 351-357.

Forsline PL, Towill LE, Waddell JW, Stushnoff C, Lamboy WF, McFerson JR. 1998. Recovery and longevity of cryopreserved apple buds. J Amer Soc Hort Sci 123: 365-370

Forsline PL, McFerson JR, Lamboy WF, Towill LE. 1999. Development of base and active collections of Malus germplasm with cryopreserved dormant buds. Acta Horticulturae 484: 75-78.

Jenderek MM, Forsline P, Postman J, Stover E, Ellis D. 2011. Effect of geographical location, year, and cultivar on survival of Malus sp. dormant buds stored in vapors of liquid nitrogen. HortScience 46: 1230-1234.

Lambardi M. 2012. From the field to the tank: The cryo-banking of ancient Italian apple germplasm by the dormant-bud technique. Cryobiology 65: 342.

Martha D. 2001. Cryopreservation of dormant vegetative buds in liquid nitrogen as an alternative method of conservation of fruit crop germplasm-review. Proceedings of $9^{\text {th }}$ International Conference of Horticulture. Lednice, Czech Republic, ISBN 80-7157-524-0, Vol. 1, pp. 55-59.

Niino T. 1995. Cryopreservation of germplasm of mulberry (Morus Species). Biotech in Agr and Fore. 32: 102-113.

Reed BM, Denoma J, Luo J, Chang Y, Towill L. 1998. Cryopreservation and long-term storage of pear germplasm. In Vitro Cell Dev Biol-Plant 34: 256-260.

Sakai A, Nishiyama Y. 1978. Cryopreservation of winter vegetative buds of hardy fruit trees in liquid nitrogen. HortScience 13: 225-227.

Sakai A. 1960. Survival of the twigs of woody plants at $196^{\circ} \mathrm{C}$. Nature 185: 393-394.

Stushnoff C. 1987. Cryopreservation of apple genetic resources. Can J Plant Sci. 67: 1151-1154.

Towill LE, Bonnart R. 2005. Cryopreservation of apple using non-desiccated sections from winter-collected scions. CryoLetters 26: 323-332.

Towill LE, Ellis DD. 2008. Cryopreservation of dormant buds. In Plant Cryopreservation-A Practical Guide, (ed) BM Reed, Springer, New York. pp.421-439.

Towill LE, Forsline PL, Walters C, Waddell JW, Laufman J. 
2004. Cryopreservation of Malus germplasm using a winter vegetative bud method: Results from 1915 accessions. CryoLetters 25: 323-334.

Tyler NJ, Stushnoff C. 1988. Dehydration of dormant apple buds at different stages of cold acclimation to induce cryopreservability in different cultivars. Can J Plant Sci. 68: 1169-1176.

Tyler NJ, Stushnoff C. 1988. The effects of prefreezing and controlled dehydration on cryopreservation of dormant vegetative apple buds. Can J Plant Sci. 68: 1163-1167.

Tyler NJ, Stushnoff C, Gusta LV. 1988. Freezing of water in dormant vegetative apple buds in relation to cryopreservation. Plant Physiol. 87: 201-205.

Vogiatzi C, Grout BWW, Wetten A. 2012. Cryopreservation of winter-dormant apple: III-Bud water status and survival after cooling to $-30^{\circ} \mathrm{C}$ and during recovery from cryopreservation CryoLetters 33: 160-168.

Wu Y, Zhao Y, Engelmann F, Zhou M, Zhang D, Chen S. 2001. Cryopreservation of apple dormant buds and shoot tips. CryoLetters 22:375-380.

http:/www.karin.re.kr: Korea Agricultural-economic Research Information Network 